\title{
NONSTRUCTURAL PROTEINS OF HUMAN CORONAVIRUS NL63
}

\author{
Yvonne Piotrowski, Lia van der Hoek, Krzysztof Pyrc, Ben Berkhout, \\ Ralf Moll, and Rolf Hilgenfeld*
}

\section{INTRODUCTION}

In March 2004, a new human coronavirus was identified in The Netherlands. Named HCoV-NL63, it was found to cause acute respiratory disease in both children below the age of 1 and immunocompromised adults. ${ }^{1}$ HCoV-NL63 belongs to the first of the three groups the coronaviruses have been subdivided into. Its plus-strand RNA genome consists of 27,553 nucleotides and a poly-A tail. At variance with typical group 1 coronaviruses, HCoV-NL63 has an additional 179-amino acid residue domain in the Sprotein and only one open reading frame (ORF) instead of two between the $\mathrm{S}$ and the $\mathrm{E}$ gene. ${ }^{1}$ Very recently, it was found that the HCoV-NL63 spike-protein binds to the SARS$\mathrm{CoV}$ receptor angiotensin-converting enzyme 2 (ACE-2) but not to $\mathrm{CD} 13$ as other group I coronaviruses. ${ }^{2}$ The genome of all known coronaviruses contains two ORFs that encode nonstructural proteins, and these are followed by the genes encoding the four structural proteins. Nonstructural proteins play an essential role in the replication and transcription of the virus genome as well as in polyprotein processing. Elucidating their structures and functions will pave the way for anticoronaviral drug discovery.,4

\section{MATERIALS AND METHODS}

Cloning: To create expression clones of the genes encoding the non structural proteins of HCoV-NL63, we decided to apply TOPO cloning in combination with bacteriophage lambda recombination technology (Gateway technology by Invitrogen) instead of the commonly used T4-DNA ligase. In the TOPO reaction, the insert, modified by adding a 4-nucleotide sequence (CACC) at the 5' end, has been cloned using topoisomerase I in the correct orientation into the entry vector $p E N T R / D-T O P O$. In the following LR recombination reaction, the insert was transferred from the entry vector

*Yvonne Piotrowski, Ralf Moll, Rolf Hilgenfeld, University of Lübeck, 23538 Lübeck, Germany. Lia van der Hoek, Krzysztof Pyrc, Ben Berkhout, University of Amsterdam, 1105 AZ Amsterdam, The Netherlands. 
into the expression vector pEXP1-DEST using clonase. It contains the bacteriophage lambda recombination proteins integrase (Int) and excisionase (Xis) and the E. coliencoded protein integration host factor (IHF), and promotes in vitro recombination between an entry clone (att $\mathrm{L}$-flanked gene) and the attR-containing destination vector to generate an $a t \mathrm{~B}$-containing expression clone.

Protein production, purification, and characterization: Expression was performed in E. coli BL21 Gold (DE3). Cultures were grown in YT medium. Expression was induced at $\mathrm{OD}_{660 \mathrm{~nm}}=0.4$ by adding $1 \mathrm{mM}$ IPTG. For test expression of the generated constructs, cells were harvested by centrifugation after 6 hours of incubation either at $37^{\circ} \mathrm{C}$ or $20^{\circ} \mathrm{C}$. Samples were analyzed by SDS-PAGE and immunoblotting. For large-scale protein production of $\mathrm{HCoV}-\mathrm{NL} 63 \mathrm{Nsp} 9$, cultures were incubated at $37^{\circ} \mathrm{C}$ for 6 hours, the bacterial pellets were resuspended in $50 \mathrm{mM}$ Tris, $500 \mathrm{mM} \mathrm{NaCl}, 20 \mathrm{mM}$ imidazole, 0.1 $\mathrm{mM} \beta$-mercaptoethanol, $\mathrm{pH} 7.5,1 \%$ Tween $20,10 \mathrm{mg}$ lysozyme/l cultivation volume, incubated on ice for 30 minutes and disrupted by French Press. After ultracentrifugation, the protein in the supernatant was purified by Ni-NTA-agarose chromatography.

The protein was eluted using a linear gradient from $20 \mathrm{mM}$ to $500 \mathrm{mM}$ imidazole with $50 \mathrm{mM}$ Tris, $500 \mathrm{mM} \mathrm{NaCl}, 0.1 \mathrm{mM} \beta$-mercaptoethanol, $\mathrm{pH}$ 7.5. The pooled fractions containing the protein were dialyzed against $50 \mathrm{mM}$ Tris, $100 \mathrm{mM} \mathrm{NaCl}, \mathrm{pH}$ 7.5, and concentrated in an Amicon ultrafiltration cell.

Spectroscopic investigations. Dynamic light scattering: Dynamic light scattering (DLS) is a method for measuring the size of molecules and particle dispersion. It is useful as a pre-screen to find optimum protein crystallization conditions. A low polydispersity (width of the size distribution) is promising for crystal growth. The spectra were recorded using a Laser-Spectroscatter 201 (RiNA GmbH Netzwerk RNA Technologies). Twenty microlites of the protein solution, as used for the crystallization attempts, were measured in quartz glass cuvettes (light path: $10 \mathrm{~mm}$, broadness of light accessible window: 1.5 mm, Hellma).

Fluorescence spectrometry: RNA binding to Nsp9 was followed by measuring fluorescence quenching of the single tryptophan residue in the protein using a Cary Eclipse fluorescence spectrometer (Varian). Spectra were measured using an excitation wavelength of $280 \mathrm{~nm}$ and emission wavelengths between 290 and $540 \mathrm{~nm}$.

The titration experiment was carried out in a 500- $\mu 1$ quartz fluorescence cuvette containing $10 \mu \mathrm{M}$ protein in $50 \mathrm{mM}$ Tris, $100 \mathrm{NaCl}, \mathrm{pH}$ 8.5. Increasing amounts of a 20 mer oligoribonucleotide were added starting with $0.4 \mu \mathrm{M}$.

\section{RESULTS AND DISCUSSION}

\subsection{Cloning and Expression of Nonstructural Proteins of HCoV-NL63}

Eight out of 13 cDNAs encoding nonstructural proteins have been cloned into the entry vector $\mathrm{pENTR/D-TOPO.} \mathrm{Using} \mathrm{bacteriophage} \mathrm{lambda} \mathrm{recombination}$ technology, seven out of them could be recombined into the expression vector $p E X P 1-$ DEST. Until now, 6 genes encoding nonstructural proteins of HCoV-NL63 have been expressed successfully. Figure 1 displays the expression of Nsp3, Nsp7, Nsp8, Nsp9, and Nsp10, while the expression of Nsp5 failed using the method described. 

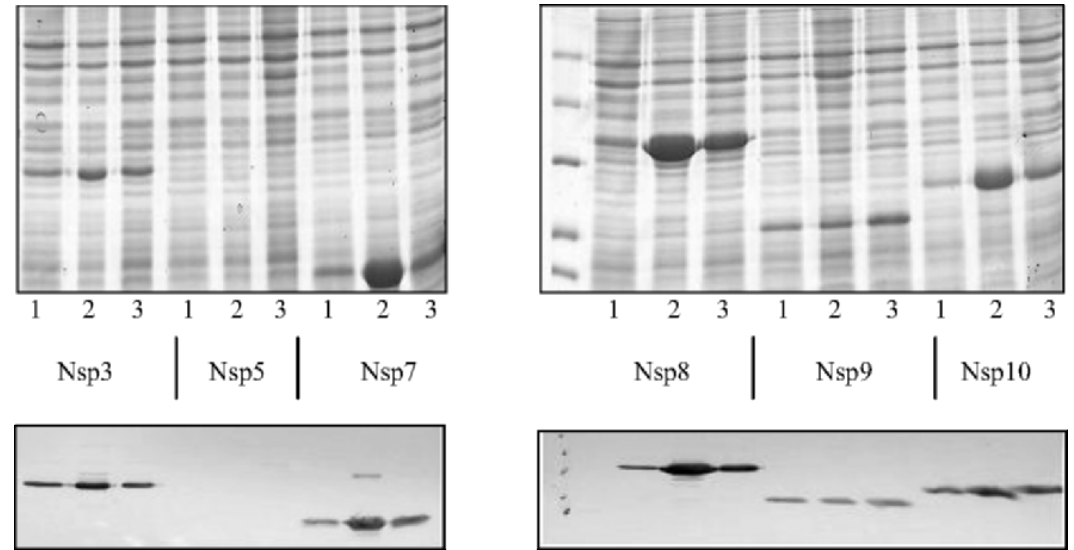

Figure 1. SDS-PAGE (above) and immunoblot with the anti-tetra-His-antibody (below), demonstrating the expression of the non structural proteins $3,7,8,9$ and 10. 1: before induction, 2: after 6 hours incubation at $37^{\circ} \mathrm{C}, 3$ : after 6 hours incubation at $20^{\circ} \mathrm{C}$.

\subsection{Nonstructural Protein 9 (Nsp9)}

Nsp9 of HCoV-NL63 consists of 158 amino-acid residues and has a molecular weight of $17.5 \mathrm{kDa}$ and a theoretical $\mathrm{pI}$ of 8.47 . The N-terminal His-tag allows singlestep purification using Ni-NTA-agarose chromatography. The purified Nsp9 can be concentrated up to $2.3 \mathrm{mg} / \mathrm{ml}$. The size of Nsp9 aggregates can be reduced by addition of detergents such as $n$-octyl- $\beta$-glucoside, as shown with the DLS (Fig. 2A/B).

The single tryptophan residue of Nsp9 is partially exposed to solvent, as found in SARS-CoV Nsp9. ${ }^{5}$ Due to this tryptophan, the fluorescence spectrum of the NL63 Nsp9 clearly displays an emission maximum at $352 \mathrm{~nm}$ (Fig. 3A). It can be almost completely quenched by adding $5.3 \mu \mathrm{M}$ of a 20 -mer oligoribonucleotide (Fig. 3B). Apparently, the tryptophan interacts with the ribonucleotide ligand suggesting that HCoV-NL63 Nsp9 is a single-stranded RNA-binding protein. The emission maximum did not change, indicating that the tryptophan residue remains in a polar environment in the presence of the oligoribonucleotide.

A

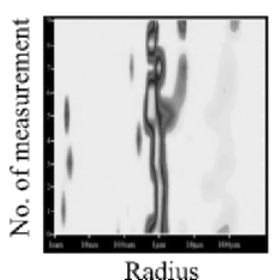

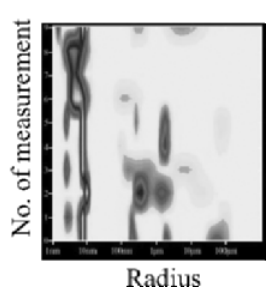

Figure 2. DLS spectrum before (A) and after incubation of the protein solution with $1 \% n$-octyl- $\beta$-glucoside (B). 


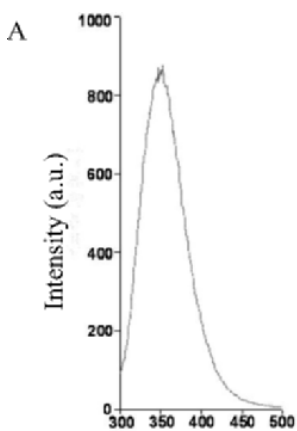

Wavelength (nm)

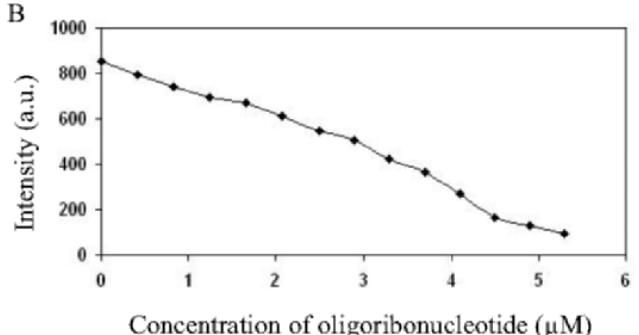

Figure 3. (A) Fluorescence spectrum of NL63 Nsp9. (B) Quenching with increasing amounts of a 20-mer oligoribonucleotide. Excitation wavelength: $280 \mathrm{~nm}$.

\section{CONCLUSIONS}

Genes coding for 6 out of 13 nonstructural proteins of the human coronavirus NL63 have been successfully expressed as soluble proteins. The purified proteins are being used for biophysical studies and X-ray crystallography to elucidate the structure and function of the HCoV-NL63 replicase complex. Combining the Gateway technology with TOPO cloning provides an easy and fast way of cloning without the requirement of ligase and post-PCR procedures.

\section{ACKNOWLEDGMENTS}

This project is being supported by VIZIER (Comparative structural genomics of viral enzymes involved in replication; contract no. LSHG-CT-2004-511960; www.viziereurope.org), an integrated project funded by the European Commission.

\section{REFERENCES}

1. L. van der Hoek, et al., Identification of a new human coronavirus, Nat. Med. 10, 368-373 (2004).

2. H. Hofmann, et al., Human coronavirus NL63 employs the severe acute respiratory syndrome coronavirus receptor for cellular entry, Proc. Natl. Acad. Sci. USA 102, 7988-7993 (2005).

3. K. Anand, H. Yang, M. Bartlam, Z. Rao, and R. Hilgenfeld, in: Coronaviruses with special emphasis on first insights concerning SARS, edited by A. Schmidt, M. H. Wolff, and O. Weber, (Birkhäuser, Basel, 2005), pp. 173-199.

4. D. A. Groneberg, R. Hilgenfeld, and P. Zabel, Molecular mechanisms of severe acute respiratory syndrome (SARS), Respir. Res. 6, 8 (2005).

5. M.-P. Egloff, et al., The severe acute respiratory syndrome-coronavirus replicative nsp9 is a single-stranded RNA-binding subunit unique in the RNA virus world, Proc. Natl. Acad. Sci. USA 101, 3792-3796 (2004). 